\title{
ORALIDADE OU ORALIZAÇÃO DA ESCRITA? UMA ANÁLISE DO LIVRO DIDÁTICO LETRAMENTO E ALFABETIZAÇÃO
}

Luciana Cristina Ferreira Dias Di Raimo (UEM) Caroline Adriana Mendes Burach (UEM)

Resumo: Este trabalho tem como objetivo, a partir do conceito de oralidade, investigar e analisar o livro didático Letramento $e$ Alfabetização, do 3o ano do Ensino Fundamental I, considerando as seções intituladas Práticas de oralidade, a fim de verificar se o trabalho com a oralidade se dá em consonância com as teorias propostas ou há incongruências na relação teoria e prática. Para tanto, toma-se como escopo teórico os postulados de Marcuschi (1997, 2001, 2007), Bakhtin (1988, 2011), bem como os documentos oficiais como Parâmetros Curriculares Nacionais (PCN) (1997) e o Ensino Fundamental de Nove anos - Orientações Pedagógicas para os Anos Iniciais (2010).

Palavras-chave: Documentos oficiais; Oralidade; Livro Didático.

Abstract: This work aims, from the concept of orality, investigate and analyze the textbook Letramento e Alfabetização, the 3rd year of elementary school, considering the sections entitled orality practices in order to verify that the work with the orality is gives in line with the theories proposed or there are inconsistencies in the relationship between theory and practice. Therefore, it takes as a theoretical scope of the postulates of Marcuschi $(1997,2001,2008)$, Bakhtin $(1988,2011)$ and official documents such as the Parâmetros Curriculares Nacionais (PCN) (1997) and the Ensino Fundamental de Nove anos - Orientações Pedagógicas para os Anos Iniciais (2010).

Keywords: Official documents; Orality; Textbook.

\section{INTRODUÇÃO}

A linguagem se efetiva de diferentes formas e em diferentes modalidades. Na contemporaneidade, faz-se 
necessário contemplar, no ensino de Língua Portuguesa, todas as práticas discursivas: oralidade, escrita e leitura. No entanto, a concepção de ensino ainda está presa a uma corrente teórica tradicional que prioriza aspectos formais em detrimento dos usos, fazendo com que a gramática continue sendo o foco das aulas em relação às demais habilidades.

Desse modo, o ensino da língua, hoje, deve-se realizar por meio de textos e não mais frases ou estruturas isoladas. Nesse cenário, a oralidade entra como uma prática discursiva que tem pouco espaço na sala de aula, pois há um consenso, entre os docentes, de que o trabalho com essa modalidade é complexo, portanto, justifica-se a necessidade de desenvolver estudos que contemple essa especificidade da linguagem.

Nesse sentido, este trabalho tem como objetivo, a partir do conceito de oralidade, investigar e analisar o livro didático Letramento e Alfabetização, do 3o ano do Ensino Fundamental I, considerando as seções intituladas Práticas de oralidade, a fim de verificar se o trabalho com a oralidade se dá em consonância com as teorias propostas ou há incongruências na relação teoria e prática. Para tanto, toma-se como escopo teórico os postulados de Marcuschi (1997, 2001, 2008), Bakhtin $(1988,2011)$, bem como os documentos oficiais 
como Parâmetros Curriculares Nacionais (PCN) (1997) e o Ensino Fundamental de Nove anos - Orientações Pedagógicas para os Anos Iniciais (2010).

Assim, o caminho teórico-metodológico empreendido neste trabalho será apresentado em três seções. Na primeira, apresenta-se como os documentos oficiais tratam a oralidade, foco de análise, além de abordar questões concernentes, como o livro didático e os gêneros textuais (orais e escritos). Na segunda parte, apresenta-se a análise de todas as seções do livro didático que tratam das práticas de oralidade. E, por fim, na última parte, apresentam-se reflexões a respeito de todo o trabalhado executado, a fim de verificar as contribuições.

\section{A ORALIDADE NOS DOCUMENTOS OFICIAIS: PCN E ENSINO FUNDAMENTAL DE NOVE ANOS - ORIENTAÇÕES PEDAGÓGICAS PARA OS ANOS INICIAIS}

Diferente do que muitos docentes pensam, a prática pedagógica não é tão autônoma quanto parece. Existem documentos, em nível nacional, estadual e até municipal, que orientam a organização das propostas curriculares das escolas e, consequentemente, das disciplinas. Um deles, os Parâmetros Curriculares Nacionais, doravante PCN, foi produzido pelo Ministério da Educação (MEC) com o intuito de conduzir o professor a obter resultados com seus alunos. 
Da mesma forma, já atualizado para as mudanças do ensino fundamental de nove anos, a Secretaria de Estado da Educação do Paraná disponibilizou um documento chamado Orientações Pedagógicas para os Anos Iniciais.

Ambos os documentos, foram construídos de forma coletiva com a participação de professores e dos órgãos gestores da educação básica. Uma das defesas principais é o respeito às diversas características que constituem o alunado - etárias, sociais, psicológicas e cognitivas. A partir disso, formar cidadãos críticos, autônomos e reflexivos que possam atuar como agentes participantes e modificadores da sociedade.

Além disso, os documentos norteadores, PCN e Orientações Pedagógicas para os Anos iniciais, estão pautados nos pressupostos teóricos bakhtinianos $(1998,2011)$ visando à dialogicidade entre o sistema e as situações reais de uso da língua. Trazendo isso para o campo do ensino, temos como equivalência a concepção de linguagem como interação, na qual o trabalho com a língua deixa de ser mecânico e oportuniza atividades que possibilita a construção do conhecimento e seus diversos usos em diferentes contextos na sociedade.

A partir de uma análise crítica, tanto o PCN (1997) como os documentos do estado do Paraná, afirmam que a criança 
aprende a falar antes de iniciar a vida escolar, mas os usos e as formas da língua oral devem ser competências da escola considerando as diferentes situações comunicativas. Dessa forma, o professor precisa ensinar aos alunos "a utilizar adequadamente a linguagem em instâncias públicas, a fazer uso da língua oral de forma cada vez mais competente" (BRASIL, 1997, p.38).

Ademais, reforçam a importância do planejamento da ação pedagógica a fim de promover reflexões sobre a língua também pela prática oral, seja em situações informais ou formais, levando em consideração os diferentes interlocutores e contextos comunicativos. Portanto,

não basta deixar que as crianças falem; apenas o falar cotidiano e a exposição ao falar alheio não garantem a aprendizagem necessária. É preciso que as atividades de uso e as de reflexão sobre a língua oral estejam contextualizadas em projetos de estudo, quer sejam da área de Língua Portuguesa, quer seja das demais áreas do conhecimento. A linguagem tem importante papel no processo de ensino, pois atravessa todas as áreas do conhecimento [...]. (BRASIL, 1997, p.39)

O documento PCN ainda orienta que a produção oral se dê em atividades coletivas que envolvam pesquisas, decisões, divisão de tarefas, apresentação de resultados, resoluções 
de problemas, verbalizações, comparações e confronto de metodologias. Além disso, deve-se trabalhar com os alunos atividades em que haja o planejamento de um texto oral, bem como a exposição oral das produções, narração de fatos pertinentes e a relação da fala do produtor com a dos demais colegas de classe. Porém, observa-se que, em tais práticas de uso da linguagem, a exposição oral é considerada uma habilidade que se adquire a partir da fala e da escrita, por isso, não costuma ser ensinada.

Para tanto, o trabalho com a oralidade, conforme o documento nacional, precisa ser gradual partindo das séries iniciais e se intensificando nas séries finais. $O$ que se propõe é que haja a articulação entre língua oral e escrita, como por exemplo, escrever um roteiro da fala e falar a partir dele, para que o aluno vá buscando autonomia até que possa planejar a atividade oral sem base escrita.

O documento produzido pela Secretária de Educação do Paraná ainda reforça a importância de trabalhar o plurilinguismo, levando para a sala de aula "músicas cantadas por intérpretes de regiões diferentes e despertar a atenção das crianças não só para os ritmos, como para as variações de sotaque e vocabulário, destacando que esse mosaico de falares representa a diversidade cultural brasileira" (GUSSO, 2010, p.14). 
Devido às mudanças de perspectivas em correntes teóricas (tradicionalismo, estruturalismo e interacionismo) e, posteriormente, concepções de linguagem (como expressão do pensamento, como instrumento de comunicação e como interação), as práticas comunicativas passaram a ser compreendidas como gêneros discursivos. O objetivo é transformar, de modo qualitativo, o ensino e a aprendizagem da Língua Portuguesa. Diante disso, ambos os documentos propõem que o trabalho com a oralidade deve se dar de modo significativo por meio da produção de gêneros como contos, mitos, lendas populares, poemas, canções, quadrinhas, parlendas, advinhas, trava-línguas, piadas, provérbios, saudações, instruções, relatos, entrevistas, notícias, debates, anúncios, seminários e palestras.

Além da produção de gêneros, deve-se trabalhar com atividades de escuta tanto por telefone, rádio ou televisão, desenvolvendo a percepção de sentido figurado, do humor, atenção às réplicas e tréplicas, nível de formalidade no uso da linguagem, planejamento e gravação de situações de comunicação oral para análise. Assim, atendendo aspectos relevantes da oralidade como entoação, dicção, gesto e postura. 


\section{FALA E ESCRITA: ASPECTOS RELEVANTES}

Após a revisão a respeito do tratamento da oralidade nos documentos oficiais, as proposições de Marcuschi (1997, 2001, 2007) são fundamentais para a compreensão dos conceitos de fala e escrita, visto os objetivos deste trabalho. Isso se justifica pelo fato de que o trabalho em sala de aula ainda apresenta certa confusão na práxis.

Toda nossa prática discursiva se dá por meio da fala (gestos, olhares, sons) e da escrita (gráfico, letras), características distintas. Percebe-se isso, pois no dia-a-dia falamos com as pessoas que estão ao redor, damos notícias, comentamos e também escrevemos bilhetes, preenchemos formulários, mandamos mensagens, entre outros. Porém, fala-se mais do que se escreve. A escrita não consegue reproduzir certos mecanismos da fala como sotaque, tom de voz, entoação, pausas, velocidade. Na escrita, isso só é possível por meio da pontuação, que representa, relativamente, o que tenta se produzir na fala.

Apesar de cooperarem no mesmo sistema linguístico, apresentam realizações e metodologias próprias. Assim, fala e escrita podem ser definidas como:

A fala seria uma forma de produção textualdiscursiva oral, sem a necessidade de uma tecnologia além do aparato disponível pelo 
próprio ser humano. Mas pode envolver aspectos muito complexos como ainda veremos, em especial quando se trata da fala em contextos muito particulares em que a oralidade é uma prática bem desenvolvida, como, por exemplo, na hora de fazer um discurso em público ou se submeter a uma entrevista de emprego. A escrita seria, além de uma tecnologia de representação gráfica da língua com base em um sistema de notação que, no nosso caso, é alfabético, também um modo de produção textual-discursiva com suas próprias especificidades. (MARCUSHI, 2007, p.40-41).

Fala e escrita variam de forma considerável, visto que a escrita apresenta mudanças estilísticas, na fala não. O que se percebe é querer normatizar a fala por meio do mesmo conjunto de regras que se aplica na escrita. Além disso, as condições de produção das duas modalidades são divergentes. Enquanto, a fala, geralmente, se dá face a face, a escrita ocorre de forma monologada sem a presença dos interlocutores. O tempo de recepção da fala é simultâneo, da escrita é retardada. Contudo, apesar das diferenças, o status de superioridade que a escrita tem é equivocado, visto que nenhuma modalidade é superior à outra.

Marcuschi (2007) apresenta um quadro das dicotomias perigosas entre fala e escrita, no qual de um lado a fala é contextualizada, implícita, concreta, redundante, não 
planejada, imprecisa e fragmentária e, de outro, a escrita é descontextualizada, explícita, abstrata, condensada, planejada, precisa e integrada. Essas são visões distorcidas, pois a língua é contextualizada, tanto os textos orais como os escritos são planejados.

O autor defende que as diferenças entre fala e escrita devem ser observadas e analisadas num processo contínuo dos gêneros textuais, e não separadamente, tal como abaixo.

\section{FALA E ESCRITA NO CONTÍNUO DOS GÊNEROS TEXTUAIS}

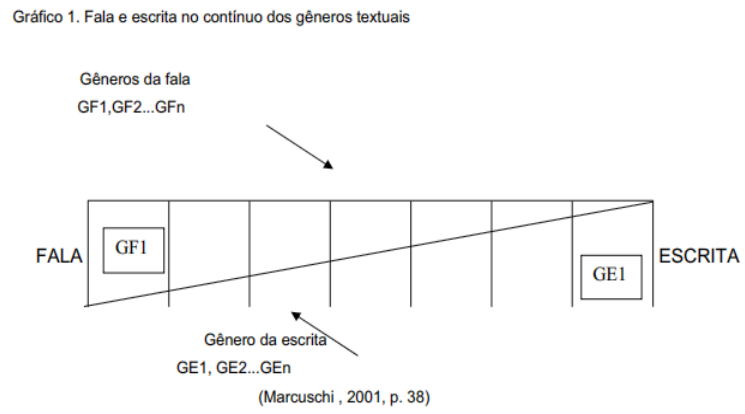

Fonte: MARCUSCHI, 2001, p. 30

No gráfico, a fala e a escrita se dão em dois domínios: a linha dos gêneros textuais (GF1, GF2... GFn e GE1, GE2 ...GEn) e das características específicas de cada modalidade. Percebe-se que o GF1 e o GE1 são gêneros típicos e não híbridos de cada modalidade e os demais vão se intercruzando por pertencer tanto a fala quanto a escrita como o gênero aviso, que tanto perpassa por ele a fala quanto a escrita. 
Marcuschi (2007) critica os dois gráficos proposto por Stubbs (1986), no qual a fala está para a informalidade e para a língua não - padrão e a escrita para a formalidade e para a língua padrão. De acordo com Marcuschi, suas suposições não foram testadas de modo concreto e efetivo, o que as tornam inviáveis, pois a escrita aparece em contextos de informalidade, como cartas, bilhetes, e a fala aparece em contextos formais como um discurso político, por exemplo.

Como já foi apresentada, a escrita possui regras próprias, para tanto, Marcuschi formula mecanismos textuais da fala como marcadores conversacionais, repetição, correção, hesitação, paráfrase, elipse, anacoluto, interjeição, parentetização, digressão e metaformulação.

Após essa breve distinção, faz-se a análise do livro didático tendo como conceito fundante a oralidade, embasada nos pressupostos teóricos de Marcuschi (1997, 2001, 2007).

\section{ANÁLISE DO LIVRO DIDÁTICO: A ORALIDADE VIA GÊNEROS TEXTUAIS}

O livro didático é um instrumento que tem como objetivo auxiliar a prática docente em sala de aula. Assim, pode ser considerado, como um elo significativo entre o professor e os alunos, mediante a exploração da leitura, compreensão de texto, oralidade e análise linguística, bem como o 
uso da criatividade e a adequação do material, levando em consideração as reais necessidades dos alunos de determinada comunidade linguística.

O livro didático a ser analisado intitula-se Letramento $e$ Alfabetização, da editora Ática, elaborado pelas escritoras Ana Trinconi, Terezinha Bertin e Vera Marchezi, destinase ao 3을 ano do Ensino Fundamental I e prescreve-se que deve ser utilizado entre os anos de 2016 a 2018, conforme as recomendações do Programa Nacional do Livro Didático. O livro é composto por doze unidades, com nove seções: gênero, interpretação do texto, práticas de oralidade, língua: usos e reflexão, produção de texto, ampliação de leitura, ortografia, hora da diversão e autoavaliação. Dentre essas seções apresentadas, interessa a este trabalho somente as seções de práticas de oralidade.

Diante disso, apresenta-se, abaixo, a primeira seção da prática de oralidade da unidade 1 que se divide em duas partes, somando quatro exercícios: 


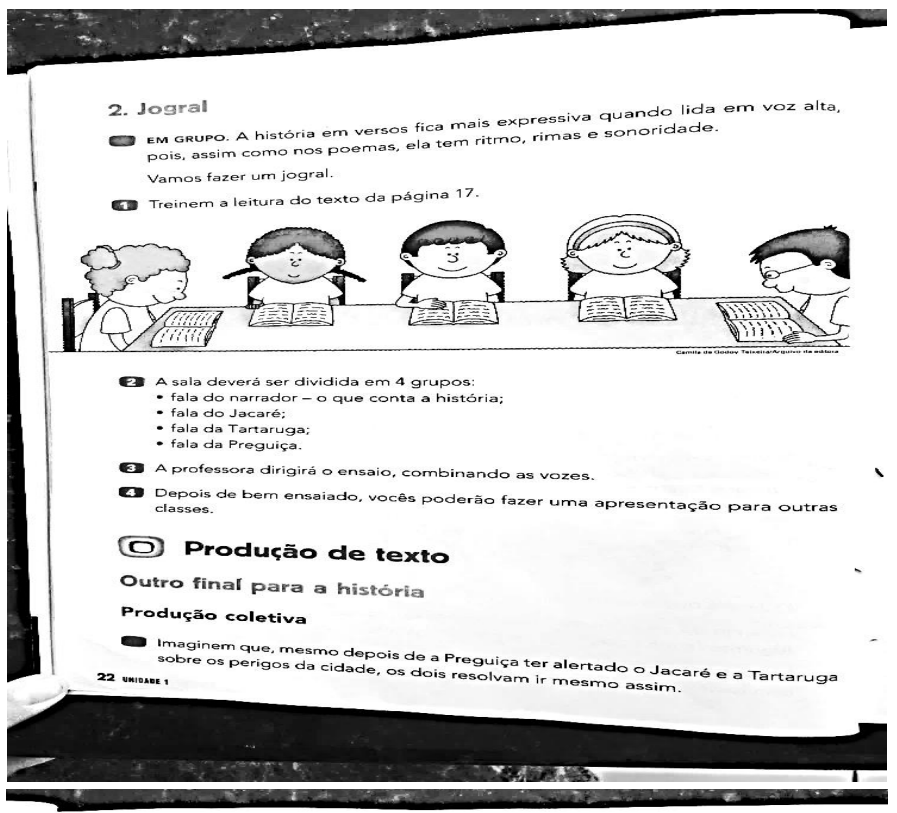

Na página 327, há um conjunto de frases fora de ordem. Recorte-as e cole-as a seguir em ordem para formar o resumo da história.

\begin{tabular}{|l|l|}
\hline Frase 1 & \\
\hline Frase 2 & \\
\hline Frase 3 & \\
\hline Frase 4 & \\
\hline
\end{tabular}

\section{(D) Práticas de oralidade}

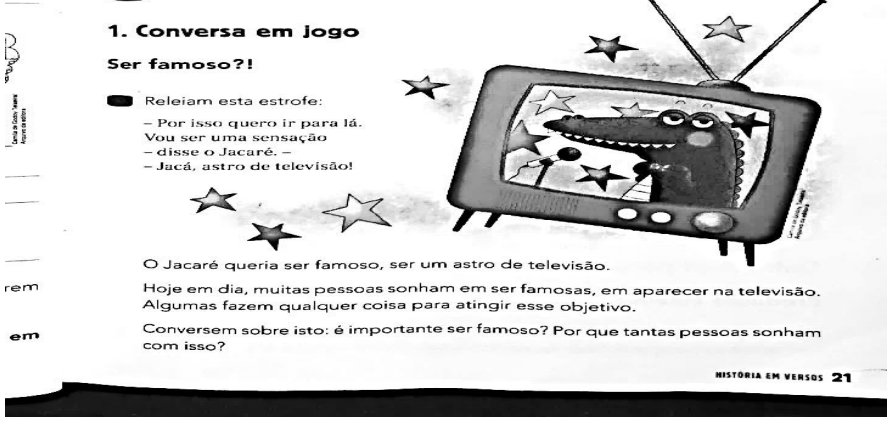

Figura 1 e 2 - Unidade 1

Fonte: Letramento e Alfabetização (2014) 
Dentre as duas atividades principais, observa-se a presença do gênero conversa e o jogral, que não é um gênero. O gênero conversa, nessa ocasião, pode ser considerado como uma prática de oralidade, uma vez que as instruções do livro são para que as crianças conversem oralmente sobre o tema fama. A "oralidade seria uma prática social interativa para fins comunicativos que se apresenta sob várias formas ou gêneros textuais fundados na realidade sonora: ela vai desde uma realização mais informal a mais formal nos vários contextos de uso" (MARCUSHI, 2001, p.21).

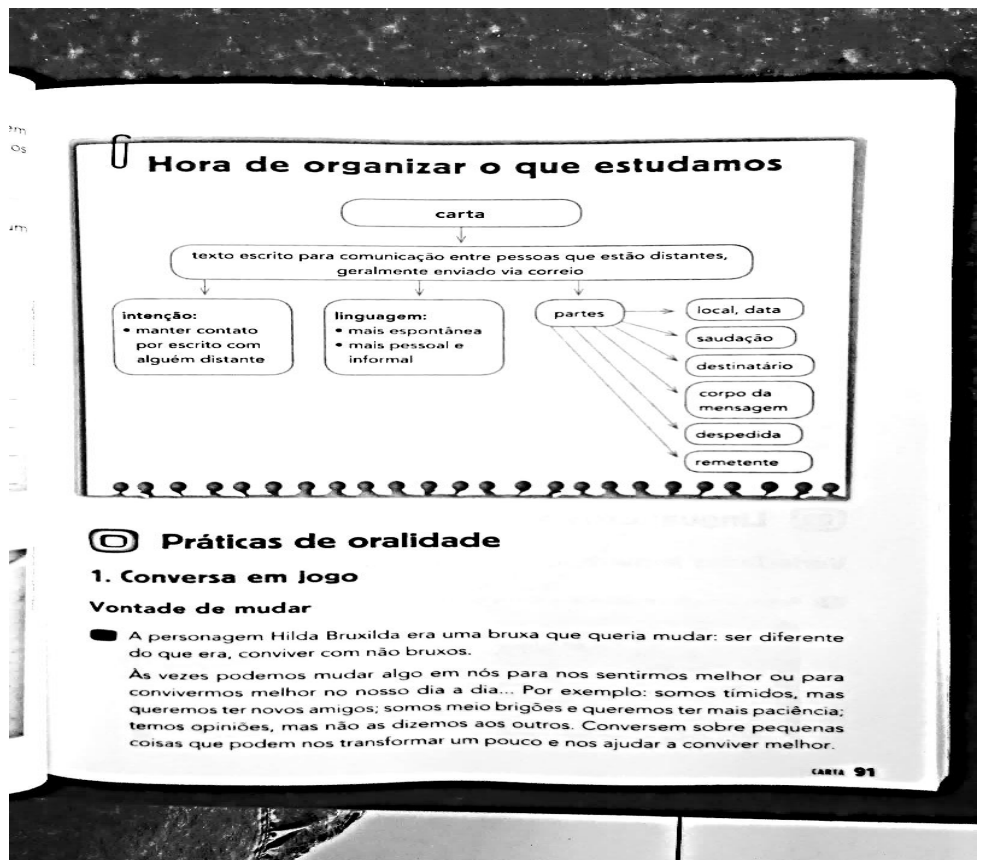




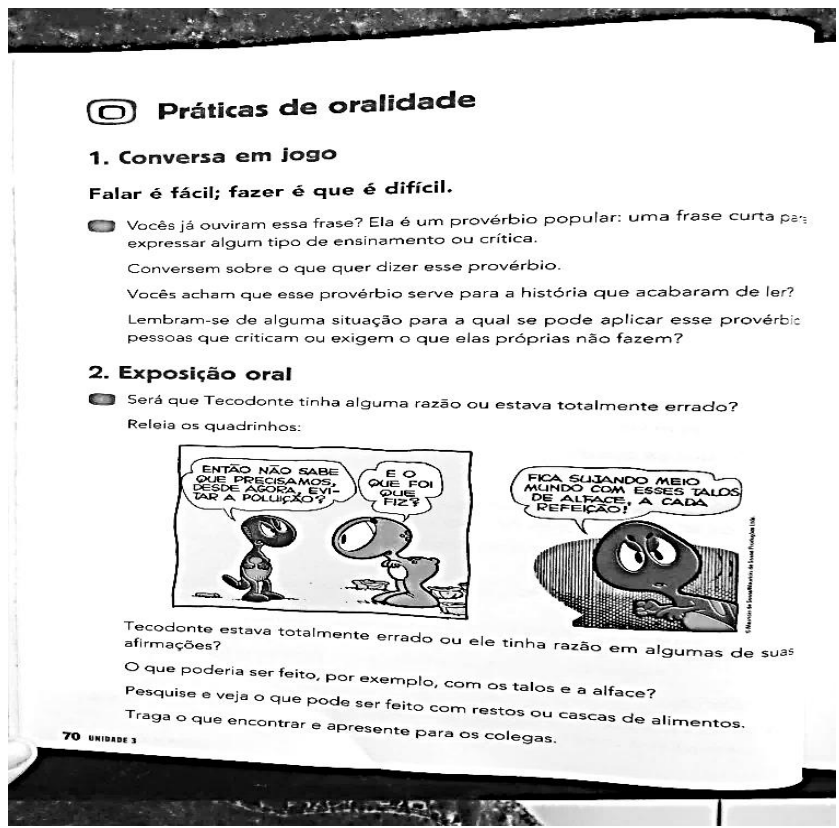

Figura 3 e 4 - Unidade 2

Fonte: Letramento e Alfabetização (2014)

Já o jogral é uma oralização da escrita, visto que trabalha com a exposição oral, mas não com a oralidade visto que tem como base o texto escrito. "Tome-se, por exemplo, o caso da notícia de um telejornal que só aparece na forma falada, mas é a leitura de um texto escrito. Trata-se de uma oralização da escrita, e não de língua oral" (MARCUSHI, 2001, p.17, grifos do autor).

Na segunda unidade, a atividade proposta é uma "dramatização do texto", na qual os alunos terão que dramatizar a história “O sapo com medo d’água”. Novamente, 
busca oralizar o texto e incentivar à expressão oral do aluno, mas não trata da oralidade. Nas instruções da atividade, pede-se que "treine bem o texto, memorizando as falas das personagens", o que configura um trabalho pautado no texto escrito, o que não é uma prática da oralidade.

Na unidade três e quatro, na seção de práticas de oralidade, na primeira atividade apresentada, pede-se para que o aluno debata sobre um provérbio. Na segunda atividade, é solicitado que o aluno leia os quadrinhos do livro didático que trata sobre a poluição de talos de alface, pesquise em casa o que pode ser feito com esses restos de alimentos e exponha para a sala a pesquisa. As duas atividades podem ser consideradas práticas de oralidade "que tem formas de textualização especiais que servem aos propósitos do armazenamento do conhecimento e que não correspondem exatamente à fala do dia-a-dia" (MARCUSHI, 2001, p.89). 


\section{(D) Práticas de oralidade}

\section{Conversa em Jogo}

\section{As aparências podem enganar}

e A fabula "O gato, o galo e o ratinho" mostra que não devemas levar em cant: apenas as aparências.

Vocè se lembra de alguma situação em que se enganou parque só levou em conta a aparéncia e năo se preocupou em conhecer melhor alguma coisa ou alguem?

Você pade pensar também em alguma história que lew ou nas que assistiw Conte o seu caso e ouça os de seus colegas.

\section{Dramatização}

E EM GRupo Organizem so para a dramatização. Distribuam os papéis, isto é. quem fará cada personagem.

Leiam o texto e memorizem as falas das personagens.

Se quiserem um narrador, ele poderá memorizar sua parte ou ler, pois ele nảo vai representar.

Podem fazer máscaras para a representação e um cenário onde a história vai
acontecer.

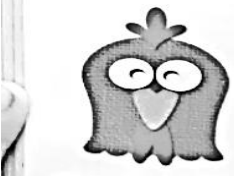

122 unionots
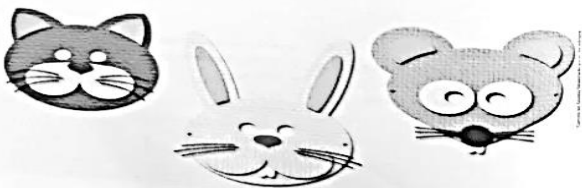

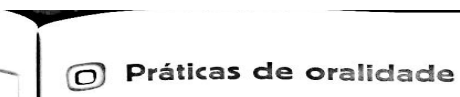

1. Conversa em jogo

Eu e os outros...

Releía estes versos:

Quando estou gigante.

Ando com cuidado

Pra nāo machucar

Quem está ao meu lado

a) Muitas pessoas se acham gigantes o tempo todo. $O$ que acontece com elas? E possivel se achar gigante em todas as ocasiōes?

b) Por que será que é preciso ter cuidado para não machucar nem magoar os outros quando nos sentimos gigantes?

c) Dê sua opiniāo e ouça a opinião dos colegas.

2. Jogral

- A professora irá dividir as vozes para os versos do poema.

Para o jogral ficar bem organizado, mesmo lendo com o livro nas mãos, todos devem treinar a leitura a pronúncia das palavras antes de iniciá-lo.

\section{(0) Memória em jogo}

Escolha a estrofe do poema "Anão e gigante" de que você mais gostou e, na página 297 escreva-a sem olhar no texto. Se auiser.

ilustre a estrofe.

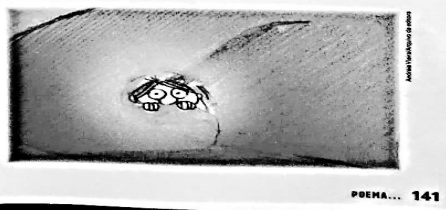

Figura 5 e 6 - Unidade 5 e 6

Fonte: Letramento e Alfabetização (2014) 
Na mesma unidade quatro, página 92, "roda de histórias fantásticas", pede-se para que os alunos vão à biblioteca, pesquisem livros de histórias maravilhosas, de encantamento, montem uma roda e leiam as histórias em voz alta para os colegas. A leitura de um texto em voz alta, não pode ser confundido com oralidade, mas é tratada como oralização, que tem como base o texto escrito.

As imagens acima, referem-se às unidades 5 e 6, no qual há a repetição do gênero textual conversa, já explicado anteriormente, e, a dramatização e o jogral que não entram nunca em classificação de gêneros textuais. O gênero conversa é um gênero típico oral, no qual, na primeira atividade os alunos devem dialogar sobre a moral de uma fábula "As aparências enganam", buscando no seu cotidiano alguém ou alguma situação que levou o aluno a se enganar por conta das aparências. Na segunda, propõe-se a leitura de versos que tratam sobre sentir-se grande e a partir disso o cuidado para não machucar/magoar os outros que estão ao redor. Essas atividades fazem com que o aluno se aproxime de sua realidade, portanto, são práticas reais de uso da língua oral. Para tanto, no momento da conversa, no diálogo há a presença de marcadores conversacionais, hesitações, repetições, paráfrases, truncamentos, recursos utilizados na fala, mudam, distorcem ou até mesmo ampliam a discussão 
do tema. As atividades de dramatização e jogral se definem, mais uma vez, como oralização da escrita.

(D) Práticas de oralidade

1. Conversa em jogo

Trabalho e estudo

5 Edgar abre 300 ostras antes da escola e 200 depois, para ajudar os pais. Voce acha isso injusto? Is so pode prejudicá-lo?

E você, também ajuda seus pais?

2. Roda de relatos pessoais

Fazer relatos sobre si mesmo é uma forma de as outras pessaas conhecerer um pouco mais sobre você.

Pense em um fato marcante em sua vida.

Lembre-se:

- de quando aconteceu

- de onde ocorreu:

- do que aconteceu.

Prepare-se para cantá-lo na roda de relatos.

E ouça com atenção o que seus colegas têm para contar.

\section{(D) Produção de texto}

Relato pessoal

ATIVIDADE ORAL E ESCRITA

6. Pree

dados serão empregados na pradução de informações que se pedem. Esse: 188 unionoe s

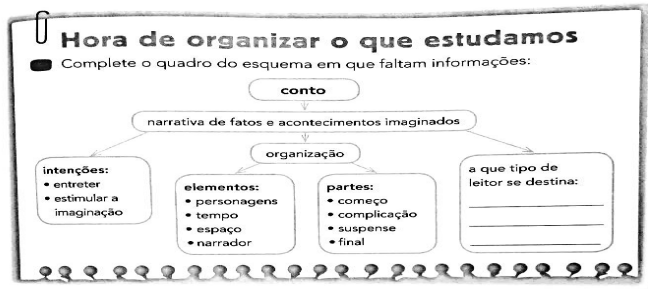

(O) Práticas de oralidade

Conversa em jogo

Ser sincero, ser autêntico...

- O alfaiate fingia cortar, costurar; os camareiros fingiam carregar o manto; as pessoas nas ruas elogiavam a "elegância" do rei por receio de passarem por bobas, para não discordar da maioria. Não tiveram opinião própria, deixaram de ser autênticas.

Hoje em dia, há pessoas que agem assim?

Conversem sobre a importância de ter opiniāo própria.

\section{(D) Conto e reconto}

- Ouça e acompanhe a leitura do conto "O jovem herói", no final do livro.

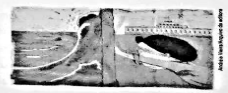

comro 165

Figura 7 e 8 - Unidades 7 e 8

Fonte: Letramento e Alfabetização (2014) 
As páginas acima são das unidades 7 e 8 . Assim sendo, todas as atividades se configuram como práticas de oralidade, uma "prática social que é inerente ao ser humano e não pode ser substituida por nenhuma outra tecnologia. Ela será sempre a porta a nossa iniciação a racionalidade. A oralidade é também um fator de identidade social, regional, grupal dos indivíduos" (MARCUSHI, 1997, p.134). Além dos gêneros já apresentados, aparecem dois novos, o conto e o relato pessoal. A atividade com o conto se dá em dois momentos, a primeira, na unidade 7, numa atividade de escuta, ponto apresentado como fundamental nos documentos oficiais e, a segunda, na unidade 9, uma atividade tanto de escuta quanto produção oral, no qual os alunos tem que ouvir um relato e depois recontar com as próprias palavras. O relato pessoal é uma prática de oralidade em que o aluno tem que relatar um fato marcante de sua vida ou de outras pessoas. Para tanto, "a escuta, ao vivo ou gravada, de autoria dos alunos ou não, é relevante para o processo de aprendizagem, pois as gravações conferem à análise um verdadeiro entendimento da relação fala - escrita [...]" (CYRANKA e MAGALHÃES, 2012, p.61). 
(D) Práticas de oralidade

1. Brincadeiras e instruçōes

EM Grupo. Vamos brincar de "batata quente"?

Antes de iniciar a jogo, leiam as regras e conversem sobre elas.

Se quiserem alterar alguma regra, ela deverá ser discutida e aceita por todos. A opinião de todos sobre a alteração de alguma das regras deve ser ouvidae respeitada.

As regras aceitas deverão ser seguidas por todos.

\section{Como brincar:}

19 Providenciem uma bola

2: Façam uma roda.

3: Fiquem sentados.

4. Um aluno, de olhos vendados, deve repetir rápido e quantas vezes desejar

"Batata quente, quente, quente, quente...". $E$, quando quiser, dizer "Queimou!".

5: Passem a bola de măo em māo enquanto o aluno fala.

6: Parem a bola quando a aluno disser: "Queimou!".

7: Deve sair da roda o aluno "queimado" que ficou cor

- que ficou com a batata quente 8. Terminem jo jarau.

9: Vence quem ficar auando todos forem "queimados"

10 : O vencedor será o próximal sem se "queimar".

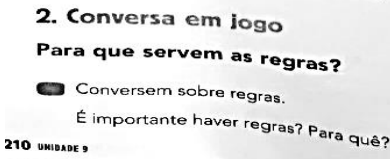

2. Conversa em logo

Para que servem as regras?

6 Conversem sobre regras.

210 unibade,

importante haver regras? Para quê?

poemas cheios de musicalidade

cavalinho

o cavalh Salles

Lá vai galopando

meu bom cavalinho,

florestas cruzando,

campinas, caminhos.

Cavalo tão belo

me leva ao castelo.

Mas dentro da noite

vai bem de mansinho.

vai bem silencioso

meu bom cavalinho.

Com cascos de prata

brilhando na mata.

Ruth Salles. As quatro árvores. São Paulo: Antroposófica, 1991

\section{(0) Práticas de oralidade}

Conversa em jogo

Voar com os pés no chão...

Pensem e conversem sobre o significado deste verso do poema "Voa ou não voa?": Será que ler é voar?

Que voo a leitura pode nos oferecer?

Quem de vocês já "voou" ao ler um livro, um poema? Qual foi o livro ou o poema?

\section{(D) Memória em jogo}

Escolha o poema de que mais gostou nesta unidade. Memorize-o e ensaie para declamá-lo para outras pessoas.

Registre na página 300 o poema escolhido de memória. Só olhe no texto se precisar.

Figura 9 e 10 - Unidades 9 e 10

Fonte: Letramento e Alfabetização (2014) 
Nas unidades 9 e 10, observa-se, novamente, a miscelânea entre oralidade e oralização da escrita. A repetição do gênero conversa é recorrente o que, de certa forma, torna o trabalho com a oralidade, pautado na informalidade, o que não é o principal objetivo exposto pelos documentos oficiais e a teoria. Em todos os momentos do trabalho com a conversa oral, não há encaminhamentos no LD que visem à formalidade ou elementos próprios da fala, como entoação, truncamentos, hesitações. Para que assim seja feito, o professor deverá adaptar e inserir esses aspectos fundantes da prática oral.

A primeira atividade de oralização proposta na seção é a brincadeira "batata quente", na qual os alunos precisam ler as regras e conversar sobre elas, caso haja discordância, podem propor alterações das regras. A segunda é a memorização de um poema de que o aluno mais gostou na unidade, sua declamação para a sala e o registro escrito na página discriminada do LD. Desse modo, os exercícios que são designados como oralidade, na verdade, são atividades de oralização da escrita que tomam como base textos escritos. 


\section{(D) Práticas de oralidade}

1. Leitura expressiva

EM GRUPo. Vocês vão fazer uma leitura expressiva do texto. Aguardem a definicaao sobre quais falas pertencem ao seu grupo.

(12) Pintem no texto as linhas $\mathrm{da} / \mathrm{s} \mathrm{fala} / \mathrm{s}$ do seu grupo

Ensaiem a/s falla/s pensando em como seria a fala de um jacaré mandão, uma anta afobada ou um macaco esperto

Ex Prestem atenção na pontuação e nas palavras do texto para caprichar na ento. naçāo, no ritmo, nos gestos, nos movimentos e nas expressōes faciais.

2. Dramatização

67. EM GRUPO. Escolham agora quem será o a tor que representará a personagem do grupo para a apresentação da peça. Ele deve memorizar as falas.

2. Ajudem na composição de cada uma das personagens, escolhen do como ser representada:

- com máscaras.

- com fantasias e/ou adereços:

- com fantoches: de vara, de luva, de sucata, etc

Escolharn o local para a representação final do texto teatral. Decidam sobre:

- o público: outras turesentar a floresta, a mudança do dia para a noite, otc).

- a divulgação da apresentação: cartazes, convidados, etc.;

- os convites para o público escolhido. ou "chamadas" escritas ou faladas

4 Leia o texto a seguir

encenaçâo da peça conheça soluçōes muito criat

274 URเIADE 12

da por llo Krugli.

\section{D) Práticas de oralidade}

1. Conversa em jogo

Modos de viver e conviver

- Depois de ouvir os relatos de cada um, conversem:

Há muitas diferenças no modo de viver de cada um? Como devemos agir dian-

te das diferenças entre as pessoas?

\section{Relato oral}

Você conheceu um pouco sobre o dia a dia das crianças que vivem à beira

do rio Amazonas e que têm de conviver com muita água durante uma boa par-

te do ano. Passam sua "infância nas águas".

Conversem sobre como é o dia a dia de cada um da turma. Vocés podem descobrir coisas interessantes sobre o modo de viver dos colegas!

1 Prepare seu relato para ser ouvido pelos colegas da classe.

a) O que você faz no dia a dia: em casa, na escola?

b) Você brinca bastante ou tem de ajudar em casa?

c) Como e o lugar onde vocé mora, como as pessoas convivem nesse lugar: são amigas ou quase não têm tempo para conversar com os vizinhos?

d) Fale de coisas de que você gosta em seu dia a dia.

(2) Espere sua vez e, quando falar, olhe sempre para aqueles que o estāo escutando. Procure falar e, quando falar, ol ous o ocam, devagar para que todos entendam Procure falar de forma que todos o ouçam, devagar pära que todos bern

(3) E, quando for sua vez de ouvir, não interrompa quem estiver falando. Mas, se precisando for sua vez de ouvir, não interrompa quem a levarde para falar. precisar perguntar alguma coisa, levante a mão e aguardo para falar.

Figura 11 e 12 - Unidades 11 e 12 Fonte: Letramento e Alfabetização (2014) 
E, por fim, as unidades 11 e 12 apresentam, na seção de trabalho com a oralidade, a variação entre oralidade e oralização da escrita. Segundo Marcuschi (2001), o trabalho com o gênero conversa escolar apresenta um elevado grau de espontaneidade e de planejamento também, e que embora apresente interlocutores definidos, não se mostram interessados na situação de comunicação oral. Já em relação ao gênero relato, o que se observa, nos dois momentos do trabalho com ele, é que não há um encaminhamento metodológico efetivo da prática oral, o que se pede, é para que o aluno espere sua vez de falar sem interromper quem está com a palavra, olhe para quem está falando e fale devagar. Essas instruções não se encaixam nas propostas tanto pelos documentos norteadores, quanto a teoria explicitada.

\section{CONSIDERAÇÕES FINAIS}

Diante das proposições dos documentos oficiais, tanto a nível nacional quanto estadual, e o percurso teórico empregado, chegam-se as seguintes considerações a respeito da análise do LD em questão.

A) O trabalho com a oralidade não acontece de forma efetiva devido à variação entre oralidade e oralização da escrita, isso se deve também ao fato de que muitos docentes confundem os dois processos, ou trata-os como similares, o que é um equívoco. 
B) A proposta nos documentos oficiais com o trabalho diversificado dos gêneros orais só se dá nas seções iniciais "gênero" de cada unidade, nas seções de "prática de oralidade" só se trabalha com o gênero conversa, conto e relato, sendo que os documentos indicam mais de vinte gêneros para serem trabalhados entre o 3ㅇ e o 4으 ano, o que daria média de dez gêneros para cada série. Essa repetibilidade do gênero conversa torna o trabalho com a oralidade informal, ponto criticado tanto pelos documentos quanto pela teoria, e impossibilita o contato e a aprendizagem dos alunos com outros contextos sociais e de usos reais da língua oral.

C) As atividades de escuta, proposto pelos documentos oficiais e pela teoria, é um aspecto pouco trabalhado pelo LD, o que também prejudica os alunos em relação ao trabalho concreto e efetivo com a oralidade.

D) E, o encaminhamento vago do LD em relação ao trabalho com a oralidade em sala de aula, visto que não há claramente a explicação de como aspectos da fala podem ser trabalhados a fim de desenvolver as habilidades orais dos alunos.

Portanto, em relação ao trabalho de modo geral com a oralidade em sala de aula, há muito que rever, principalmente o LD, que não atende minimamente as recomendações dos documentos norteadores (nacionais e estaduais) de Língua Portuguesa. 


\section{REFERÊNCIAS}

BAKHTIN, Mikhail (2011). Estética da criação verbal. São Paulo: Martins Fontes.

BORGATtO, A. M. T.; BERTIN, T. C. H.; MARChEZI, V. L. de. C. (2014). Letramento e Alfabetização. 2 ed. São Paulo: Ática.

BRASIL. Secretaria de Educação Fundamental. (1997). Parâmetros Curriculares Nacionais - 1a a $4 \underline{a}$ séries: Língua Portuguesa. Brasília: MEC/SEF. CYRANKA, Lucia Furtado de Mendonça; MAGALHÃES, Tânia Guedes. (2012). O trabalho com a oralidade/variedades linguísticas no ensino de Língua Portuguesa. Veredas on-line: Juiz de Fora.

GUSSO, A. M. et al (2010). "Língua Portuguesa" In: PARANÁ, Secretaria de Estado da Educação do Paraná. Ensino fundamental de nove anos: orientações pedagógicas para os anos iniciais. p.119-134.

MARCUSCHI, Luiz Antônio (2001). Da fala para a escrita: atividades de retextualização. São Paulo: Cortez.

. (2008) Produção Textual, análise de gêneros e compreensão. São Paulo: Parábola Editorial.

MARCUSCHI, L. A; DIONISIO, A. P. (2007). Fala e escrita. Belo Horizonte: Autêntica.

Luciana Cristina Ferreira Dias Di Raimo possui graduação em Letras pela Universidade Estadual Paulista Júlio de Mesquita Filho (1998), UNESP-ASSIS, mestrado em Letras (Filologia e Linguística Portuguesa) pela Universidade Estadual Paulista Júlio de Mesquita Filho (2001), UNESP-ASSIS e doutorado em Linguística Aplicada (área: Ensinoaprendizagem de língua materna) pela UNICAMP. Tem experiência na área de Linguística Aplicada, com ênfase na Análise do Discurso de tradição francesa, atuando principalmente nos seguintes temas: leitura, memória discursiva, identidade, brasilidade e ensino de língua materna. Com doutorado em Linguística Aplicada pela Unicamp, a pesquisadora tem seguido seus estudos e orientações de iniciação científica e TCC, a partir de reflexões produzidas com relação a processos de leitura em gêneros discursivos diversos sob um enfoque discursivo, tendo-se em 
vista a necessidade de articulação entre as dimensões do texto e do interdiscurso na produção de sentidos. Atuando, em nível de graduação, nas disciplinas de Leitura e produção de textos e Morfossintaxe, a professora está lotada no Departamento de Língua Portuguesa da UEMUniversidade Estadual de Maringá.

Caroline Adriana Mendes Burach é mestranda em Letras pela Universidade Estadual de Maringá - UEM, Área de Concentração: Estudos Linguísticos, Linha de Pesquisa: Ensino-Aprendizagem de línguas. Graduada em Letras pela Universidade Estadual do Paraná (Unespar), campus de Campo Mourão - antiga Faculdade Estadual de Ciências e Letras de Campo Mourão (Fecilcam). 